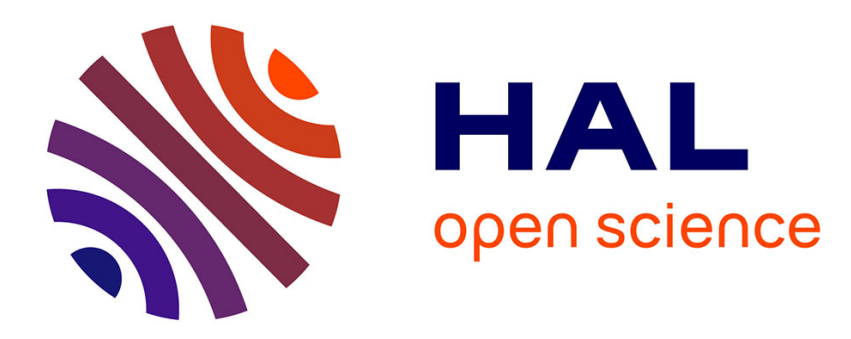

\title{
Exploring Valence in Judgments of Taste
}

Isidora Stojanovic, Elsi Kaiser

\section{To cite this version:}

Isidora Stojanovic, Elsi Kaiser. Exploring Valence in Judgments of Taste. Jeremy Wyatt; Julia Zakkou; Dan Zeman. Perspectives on Taste, Routledge, pp.231-259, 2022, 10.4324/9781003184225. hal-03469672

\section{HAL Id: hal-03469672 \\ https://hal.science/hal-03469672}

Submitted on 7 Dec 2021

HAL is a multi-disciplinary open access archive for the deposit and dissemination of scientific research documents, whether they are published or not. The documents may come from teaching and research institutions in France or abroad, or from public or private research centers.
L'archive ouverte pluridisciplinaire HAL, est destinée au dépôt et à la diffusion de documents scientifiques de niveau recherche, publiés ou non, émanant des établissements d'enseignement et de recherche français ou étrangers, des laboratoires publics ou privés. 


\title{
Exploring Valence in Judgments of Taste
}

\author{
Isidora Stojanovic (Institut Jean Nicod, DEC, CNRS, ENS, PSL) \\ Elsi Kaiser (University of South California) ${ }^{1}$
}

\begin{abstract}
Judgments of taste are often assumed to be evaluative, in the sense of expressing either a positive or a negative assessment of the object under evaluation. However, the evaluative character of predicates of personal taste (PPTs) has received relatively little attention from a semantic point of view. Our aim is to fill out this lacuna. We show that PPTs do not divide neatly into positively and negatively valenced terms. Instead, we suggest that many PPTs, such as 'surprising' and 'intense', are neutral: they are underspecified for their valence and, depending on the context, can give rise to a positive, a negative, or an ambivalent evaluation. We investigate how such neutral PPTs differ from evaluative PPTs, and how they differ from certain other terms that are neither positive nor negative, such as 'average'. We use a two-pronged approach. First, we propose two novel linguistic tests that serve as diagnostics to distinguish the class of neutral PPTs from valenced PPTs, and we use corpus examples to corroborate the tests. Second, we use information from pre-existing psychological norms of valence to further explore the class of adjectives that we hypothesize are neutral.
\end{abstract}

\section{Introduction}

In the literature on personal taste, it is often assumed that judgments of taste are evaluative; that is to say, that such judgments convey a positive or a negative assessment of the object under evaluation. The assumption is very prominent in the expressivist tradition, according to which to say/judge, for example, that the game of Monopoly is fun is analyzed in terms of recommending (approving, speaking in favor of) Monopoly, while to say that it is boring, in terms of rejecting (disapproving of, speaking against) it. Nevertheless, the evaluative character of predicates of personal taste (henceforth PPTs), in the sense of conveying something positive or negative, has received relatively little attention from a semantic point of view. This is somewhat surprising, given that the notions of evaluativity and (positive and negative) valence have been central in psychology and certain fields of philosophy (value-theory and metaethics).

Our aim in this paper is to fill out this lacuna. More precisely, we show that PPTs do not divide neatly into positively and negatively valenced terms. Instead, we argue that many PPTs, such as 'surprising', are neutral. That is to say, they are underspecified for their valence and, depending on the context, can give rise to a positive, a negative, or an ambivalent evaluation (and sometimes perhaps to no evaluation at all). Our primary aim in this paper is to investigate how such neutral PPTs differ from evaluative PPTs. We also investigate how they differ among

\footnotetext{
${ }^{1}$ Co-first authors.
} 
themselves, and how they differ from other terms (which we call middling) that are neither positive nor negative, such as 'average'.

We approach the topic of neutral PPTs using a two-pronged approach. On the one hand, we propose two novel linguistic tests that serve as diagnostics to distinguish the class of neutral PPTs from valenced PPTs. We use corpus examples to corroborate the tests. On the other, we use information from pre-existing psychological norms of valence (Warriner et al. 2013) to further explore the class of adjectives that we hypothesize are neutral. This combination of linguistic tests, corpus examples and large-scale data based on psychological norms opens up a novel research perspective. What emerges is a rich and diverse class of neutral PPTs. We identify a set of subjective adjectives with features importantly different from the paradigmatic ones like 'fun' and 'boring', yet which have gone largely overlooked in the buoyant research on PPTs. We suggest that neutral PPTs come in at least three subtypes, which we call the difficulty class, the excess class and the surprise class. We do not intend this to be an exhaustive classification. We also explore a fourth class, middling adjectives, whose status as PPTs is somewhat less clear.

We have purposefully cast a wide net in terms of the adjectives that we explore (and we do not claim that all of the adjectives that we discuss pattern uniformly in all respects), since one of our goals is to broaden the empirical basis of the kinds of adjectives that are discussed in relation to judgements of taste.

The paper is structured as follows. Section 2 addresses the question of how to delineate PPTs in the first place. In a nutshell, PPTs are a subclass of a broader class of subjective terms, and those only partially overlap with evaluative terms. Three linguistic tests to distinguish PPTs commonly used in the literature are introduced and discussed. We also clarify what we mean by 'evaluative', in contrast to some other ways in which the term has been used in the literature. In section 3, we present two new tests to distinguish neutral PPTs: (i) the Attitude Compatibility Test (AC Test) which probes the compatibility of attributing a PPT with both a positive and a negative attitude toward the object at stake, and (ii) the GOOD/BAD WAY test which assesses the possibility of modifying the adjective with "in a good/bad way." We show that neutral PPTs pass these tests, in contrast to evaluative PPTs. In section 4, we discuss data from psychological norms, which we propose can allow further insights into the class of neutral PPTs. Section 5 focuses on what we call "middling" adjectives, which we suggest need to be distinguished from the other neutral PPTs. Section 6 concludes.

\section{What are PPTs?}

Our paper focuses on predicates of personal taste that cannot be easily categorized as either positive or negative; that is to say, on neutral PPTs. But before we look more closely at such neutral PPTs, it will help to clarify what we take to be PPTs in the first place. Although the term has been firmly established in the literature, there is no consensus on how predicates of personal taste should be identified. Some authors see them as a very broad category that includes any kind of expression sensitive to a subjective point of view, including moral, 
epistemic and gradable adjectives (Kölbel 2002, Lasersohn 2005, Sundell 2011, Umbach 2016, 2020, a.o.). ${ }^{2}$ Other authors are more restrictive (Stephenson 2007, Moltmann 2011, Pearson 2013, McNally and Stojanovic 2017, Rudolph 2021, a.o.). We belong among the latter. In this section, we present three linguistic criteria on which we rely to identify PPTs (2.1), and we clarify how we understand the relationship between PPTs, subjective and evaluative predicates (2.2).

\subsection{Three tests for PPTs}

In his seminal paper on PPTs, Lasersohn writes: "Exactly which predicates qualify as predicates of personal taste is an interesting question. (...) We will concentrate here on relatively mundane predicates such as fun and tasty, and leave open the status of more philosophically "charged" predicates like good and beautiful. I do not offer here any firm diagnostic criteria for identifying predicates of personal taste, though I will return to this question briefly (...). Despite the absence of such criteria, I think the intuitive idea should be reasonably clear." (2005: pp. 644-5). And when he returns to the question, after considering a possible criterion related to the modification by to/for prepositional phrases and finding it problematic, Lasersohn concludes: "at present I see little reason to expect that subjective predicates may be identified by any straightforward linguistic test; it may be that the status of predicates must be argued for more on philosophical than linguistic grounds, on a case-by-case basis" (2005: 682-3).

We are less optimistic than Lasersohn on the claim that "the intuitive idea should be reasonably clear", yet more optimistic than him on the prospects of using linguistic tests to distinguish PPTs. And, while Lasersohn appears to use the terms PPT and subjective predicates interchangeably, we take the class of subjective predicates to be wider than that of PPTs.

To identify PPTs, we shall rely on the linguistic tests commonly used in the literature; see e.g. Umbach 2020 for a very recent overview. ${ }^{3}$ Let us present the tests first, and then briefly comment on their applicability.

\section{a) The FIND Test:}

PPTs embed felicitously under attitude verbs such as "find", as illustrated by the following contrast:

$\checkmark$ I find the game of Monopoly (to be) boring.

\# I find the game of Monopoly (to be) invented by an American.

\footnotetext{
${ }^{2}$ Kölbel (2002) does not use the expression "predicate of (personal) taste", introduced three years later in Lasersohn (2005). Nevertheless, he seems to group together into one and the same class all subjective predicates.

${ }^{3}$ Umbach writes: "customary criteria are (a) the intuition of faultless disagreement, (b) grammaticality of experiencer arguments, (c) the acceptability of embedding under subjective attitude verbs like English find, and (d) the behavior of the comparative form with respect to (a)-(c)" (Umbach 2020: p. 1). There are a few other tests to be found in the literature. One such test relies on the idea that PPTs typically trigger a so-called acquaintance inference (see Ninan 2014). The idea is that a sentence such as "Monopoly is boring, but l've never either played it or watched it" is infelicitous; but not so if 'boring' is replaced by a factual expression such as "invented by an American", or even "expensive" or "popular". Another test, proposed in McNally \& Stojanovic (2017), looks at the implications of embedding an adjective under "looks (to me)" and "sounds (to me)" (2017: p. 27). Last but not least, Soria Ruiz \& Stojanovic (2019) offer a series of criteria that are meant to identify not PPTs per se, but expressive uses of all kinds of terms.
} 


\section{b) The TO/FOR Test:}

PPTs are felicitously modified by "to -" and "for -" phrases and dative-like constructions, as illustrated by the following contrast: ${ }^{4}$

$\checkmark$ Monopoly is boring to me/to kids.

\# Monopoly was invented by an American to me/to kids.

c) The Faultless Disagreement (FD) Test:

In contexts of disagreement, PPTs trigger the intuition that neither party need be wrong, as illustrated by the following contrast:

(1a)

Peter: "Monopoly is boring."

Mary: "No, it isn't! "

$\checkmark$ If Monopoly is boring to Peter, but not to Mary, then neither of them speaks falsely.

(1b)

Piotr: "Monopoly was invented by an American."

Maria: "No, it wasn't."

x If Piotr thinks that Monopoly was invented by an American, and Maria thinks that it wasn't,

then neither of them speaks falsely. ${ }^{5}$

All three tests are problematic. The FIND Test may be traced back to Sæbø (2009), who uses it not only to delineate PPTs, but also to argue that they are sensitive to an experiencer argument. The test is further elaborated in Bylinina (2014). McNally and Stojanovic (2017) additionally use the FIND test to delineate PPTs from expressions that are evaluative but experiencerinsensitive, specifically certain aesthetic adjectives, while Stojanovic (2019) uses it to distinguish PPTs from moral adjectives. However, there is considerable disagreement on whether the verb 'find' selects for experiencer sensitive adjectives rather than a broader class of subjective adjectives; for discussion, see e.g. Coppock (2018), Kennedy and Willer (2016), Franzén (2018), Stojanovic (to appear), Willer (to appear). What is more, there is considerable crosslinguistic variation between the English 'find' and its equivalents (when there are such) in other languages, such as 'finden' in German (see Umbach 2017) or 'tycka' in Swedish (see Coppock 2018). In sum, then, paradigmatic PPTs are clearly felicitous under 'find' while factual expressions are clearly infelicitous, but there also appears to be a wide range of expressions whose behavior in these constructions is less well understood.

\footnotetext{
${ }^{4}$ As we emphasize shortly, it is quite crucial that the modification should bear on the PPT directly, rather than the entire sentence. For instance, "To me, Monopoly is an American game" is felicitous as a way of expressing one's belief that Monopoly is an American game (or perhaps more accurately, one's inclination to characterize it as an American game), even though "(to be) an American game" is clearly not a PPT. Hence, this kind of sentence-level modification is not relevant to our discussion.

${ }^{5}$ We use the symbol \# to denote infelicity, and $\boldsymbol{x}$ to denote falsity.
} 
The problems with the TO/FOR Test stem from the highly polysemous character of these prepositions. With PPTs such as 'boring' and 'tasty', the preposition introduces an experiencer argument. But the same prepositions are also used to articulate other kinds of arguments, in particular beneficiary arguments: for example, "Milk is good for kids" does not mean that kids are experiencing milk as good, but rather, that they are benefiting from it. Furthermore, especially when used at the beginning of a sentence, 'to-' and 'for'-constructions can be used to mean that the sentence reports someone's views or opinion, as in: "To a kid who grew up as an altar boy, having the pope here was a big deal" (example found in COCA; Davies 2008). (See also Stephenson 2007 who notes that the choice of the preposition that introduces the experiencer appears to be idiosyncratic.) Hence, while it remains true that an expression that cannot be felicitously modified by a 'to' or a 'for' phrase is not a PPT, the fact that an expression can be so modified is not yet sufficient to make it qualify as a PPT.

When it comes to the Faultless Disagreement Test, several worries arise. First, people may have diverging intuitions on how faultless a given disagreement may be. Even in such simple cases like (1a), some people might insist that either Peter or Mary is right. This tends to happen even more when people are biased, in the sense that they have an opinion of their own as to whether Monopoly is boring or not. Additionally, further information on the context in which a dialogue like (1a) takes place can pull one's intuitions of faultlessness in one direction or another (see Stojanovic 2007). Second, faultlessness appears to be a matter of degree. Thus Goodwin and Darley (2008) conducted a study in which they wanted to see whether disagreements over moral issues are perceived as subjective, and compared them to disagreements over factual issues, disagreements over matters of taste, and disagreements over social conventions. What they found was that moral disagreements are perceived as significantly more subjective than both factual disagreements and disagreements over social conventions, but at the same time, significantly less subjective than disagreements over taste. In other words, the FD Test appears to require a yes-no answer, while there are disagreements for which participants prefer a graded answer: faultless to a certain degree. Results that go in the same direction have been presented in Solt (2016) and Soria Ruiz \& Faroldi (2020). Thirdly, faultless disagreement can often result from a disagreement on how to understand certain terms and concepts; that is, a metalinguistic disagreement (see Barker 2002, Sundell 2013, Stojanovic 2012). Fourthly, Kaiser \& Rudin $(2020,2021)$ and Rudin \& Kaiser (to appear) present experimental data showing that the empirical profile of FD is more complex than often acknowledged, and that people's judgements of FD are influenced by factors that go beyond the subjective predicate itself -- including the object of predication, properties of the interlocutors, and even the judge's own attitudes. As a whole, these observations imply that the FD Test is too broad to track any specific lexical class, hence it is crucial to use it in combination with other diagnostics. ${ }^{6}$

Finally, a challenge that arises not just for these three tests, but for the test methodology in general, including the two new tests that we present in Section 3, is that they rely on felicity

\footnotetext{
${ }^{6}$ It bears mentioning that there is a rich literature on faultless disagreement in philosophy, with which we cannot engage in the present paper. For recent surveys, see e.g. Zakkou (2019) and Zeman (2020).
} 
judgments regarding sentences that are presented out of context. What one ordinarily does in such a case, presumably, is to generate some kind of default context. Thus, if an expression tends to sound felicitous in such a default context, it passes the test, and if it tends not to, it fails the test. We acknowledge that this leaves room for expressions for which, with enough creativity, one could come up with a particular context in which it may sound felicitous. However, in the discussion that follows, we focus on whether expressions sound felicitous without such special 'contextual contortions'. In other words, we do not focus on the possibility of coming up with a special context in which an expression seems to pass the test, even when it normally does not. Such a context is not sufficient to make the expression pass the test. What is relevant for us is whether the corresponding felicity judgments should not rely on any special contextual features, and that the expression passes the test consistently and systematically, even when presented out of context.

Despite these challenges, the linguistic tests still constitute an efficient methodology for investigating the typology of adjectives. Even if one can potentially come up with a context in which some expression that one would not want to include among PPTs appears to pass the tests, genuine PPTs pass the tests systematically. This is partly reflected in the frequency in which PPTs, as opposed to other adjectives, occur embedded under 'find' or modified by 'to-' or 'for-' phrases. Let us illustrate the point with the FIND Test. Consider the moral term "wrong", as in "I find lying wrong". The combination does not sound infelicitous - at least, not to the same degree as it does with terms such as "invented". Nevertheless, this does not put the expression "wrong" on a par with PPTs, for two reasons. First, even if such uses are possible, they are arguably statistically marginal. Some evidence to this effect is given in McNally and Stojanovic (2017), who report corpus data regarding the verb 'find' that show that most occurrences involve experiencer-sensitive adjectives such as 'difficult'. Second, as argued in Stojanovic (2019), even if the adjective itself is not sensitive to an experiencer argument, as in the case of 'wrong', embedding it under 'find' can coerce the whole embedded construction into one that is sensitive to an experiencer. In other words, "I find lying wrong" would be tantamount to saying that the speaker's judgment that lying is wrong is based on their personal experience. In sum, although some non-PPT adjectives can sometimes pass some of the three linguistic tests, PPTs pass them more consistently and reliably.

What is more, the performance of these tests may be enhanced by applying them not only to the positive form of a predicate, but also to the comparative form (see i.a. Bylinina 2014, Umbach 2020). This will set apart adjectives such as 'expensive' from genuine PPTs:

(2a) $\checkmark$ I find Monopoly expensive.

(2b) $\checkmark$ I find Monopoly boring.

(2c) ?? I find Monopoly (to be) more expensive than Catan.

(2d) $\checkmark$ f find Monopoly (to be) more boring than Catan. 
(3a) $\checkmark$ Monopoly is expensive for me.

(3b) $\checkmark$ Monopoly is boring to me.

(3c) ?? Monopoly is more expensive than Catan for me.

(3d) $\checkmark$ Monopoly is more boring than Catan to me.

(4a)

Peter: "Monopoly is more expensive than Catan."

Mary: "No, it isn't. Catan is more expensive."

(4b) Piotr: "Monopoly is more boring than Catan."

Maria: "No, it isn't. Catan is more boring."

While the disagreement between Piotr and Maria (4b) appears to be faultless, Peter and Mary's (4a) clearly isn't.

\subsection{PPTs, subjectivity and evaluativity}

Let us take stock. We have presented three tests that we take to jointly identify the class of PPTs, and at the same time, we have acknowledged that there are other adjectives that sometimes pass some of these tests, although less consistently and reliably than PPTs. Some adjectives, such as 'expensive', pass the three tests, but only when used in the positive form, which sets them apart from PPTs. Other adjectives pass the FIND test - at least to a certain extent - and the FD test, both in the positive and in the comparative form, but fail the TO/FOR test. And, in fact, certain authors consider the FD test and, especially, the FIND test, as crucial (see e.g. Franzén 2020, Silk 2021, Willer (to appear)).

Given this adjectival diversity, it is natural to wonder whether there is a broader class that consists of expressions that are not PPTs but have important features in common with them. We propose, indeed, that PPTs are a subtype of a broader category of subjective terms. We can potentially identify several other subtypes:

- moral and deontic terms, such as 'wrong', '(un)ethical', 'cruel', 'generous', 'important' and 'valuable' (see e.g. Portner and Rubinstein 2016, Stojanovic 2019, Soria Ruiz and Faroldi 2020)

- $\quad$ epistemic terms, such as 'likely', 'possible', 'credible', as well as epistemic modals (e.g. Kaiser 2015, Umbach 2020)

- $\quad$ aesthetic adjectives, such as 'beautiful', 'ugly', 'elegant' and 'garish' (e.g. McNally and Stojanovic 2017)

- psychological adjectives, such as 'painful' (Korotkova 2016) and emotional adjectives, such as 'sad' (e.g. Stojanovic 2012)

We do not claim that this typology carves up the space neatly. To the contrary, we expect there to be substantive overlap among these subtypes. For example, 'surprising', which will be one of 
our core examples of PPT discussed in later sections, can have an epistemic sense. Similarly, many PPTs and psychological predicates are often used to express aesthetic and moral properties: 'disturbing', 'disgusting', 'inspiring', and so on. Finally, given that PPTs are by their very nature closely tied to experience, the boundary between PPTs and psychological adjectives is bound to be blurry; for instance, 'pleasant' and its antonym, 'unpleasant', are often seen as paradigmatic examples both of PPTs and psychological adjectives. And again, 'surprising' is both a PPT and an emotional adjective, expressing the emotion of surprise.

Assuming that it makes sense to talk of such a broader phenomenon of subjectivity, the next question is how it relates to evaluativity. In other words, which subjective expressions are evaluative, and are there evaluative expressions that are not subjective? The answer depends, at least partly, on the choice of terminology. In fact, some of the literature uses the term 'evaluative' as an umbrella term for the broader category of expressions for which we are using here 'subjective' (e.g. Franzén 2020, Umbach 2021, Silk 2021). ${ }^{7}$ Let us, then, try to briefly explain how we understand evaluativity (for a more extended discussion, see Stojanovic (to appear)).

Pekka Väyrynen has proposed that "evaluation might (...) be understood as information to the effect that something has a positive or negative standing —-merit or demerit, worth or unworthrelative to a certain kind of standard" (Väyrynen 2013: 29). ${ }^{8}$ This characterization of evaluativity brings together two important ideas: on the one hand, the idea of valence - positive vs. negative - , and on the other, that of relativity to a standard. While standard-relativity is certainly central to the way in which, for instance, Bierwisch (1989) and Silk (2021) approach evaluative (or evaluational) adjectives, it is an aspect to which we will pay little attention here. Rather, we shall focus on the idea that "evaluative" expressions are intimately tied to the notion of expressing something positive or negative about their subject. Now, it takes little to observe that pretty much any expression can be used, in a suitable context, to express something positive or negative. If Piotr tell Maria "it is raining" in a context in which they are planning to go to the beach, his utterance will convey negative information, but if he announces it after a long heatwave in reply to Mary's worry that the plants may not survive, then it will convey positive information. We acknowledge that ordinary expressions can be used to convey evaluation, but we propose to call "evaluative" only those expressions that achieve this at least partly in virtue of their meaning. To drive the point home, then, a term is evaluative if it expresses, in virtue of

\footnotetext{
${ }^{7}$ More precisely, Silk (2021) coins a new term, 'evaluational'. Our use of 'subjective', while in line with the literature (see Willer (to appear)), is not completely unproblematic either. In particular, it may be objected that whether moral and deontic judgments and (perhaps to a lesser extent) aesthetic judgments are "subjective" has always been a matter of controversy. Let us stress that by choosing to call the broader category 'subjective', we do not mean to commit to any philosophical view regarding the status of such judgments.

${ }^{8}$ Väyrynen attributes the idea to Williams (1985, p. 125), and notes that "Mere reference to a degree that exceeds a contextually specified standard isn't sufficient for evaluation in this sense" (ibid.). The alternative sense corresponds, precisely, to how the term 'evaluative' is used in some of the linguistic literature; namely: "An adjectival construction is evaluative if and only if it conveys that the property associated with the adjective exceeds a relevant threshold" (Brasoveanu \& Rett 2017: 1). This somewhat technical sense of 'evaluative' will not be relevant to our discussion.
} 
its meaning, information to the effect that something has a positive or negative standing (relative to a certain kind of standard).

With this clarification in place, let us return to our question: are subjective terms, and PPTs in particular, evaluative? Many of them appear to be. To say that something is delicious, yummy or fun is to express something positive about it; to say that it is disgusting, yucky or boring is to express something negative. The idea that PPTs are, in general, evaluative is reflected in the way in which disagreements over taste are most often introduced. The idea of faultless disagreement is typically presented as a disagreement between speakers with clashing conative attitudes. In saying that Monopoly is boring, Peter expresses his dislike of Monopoly; in contradicting Peter by saying that it is fun, Mary expresses her positive appreciation of the game. ${ }^{9}$ While many PPTs are evaluative, and while the ones typically discussed in the literature (tasty, fun, boring) are, we believe that there are also many PPTs that are not evaluative in this sense. However, deciding which ones are and which ones are not is far from trivial. The main goal of our paper is, indeed, to delineate the class of neutral PPTs by using two distinct, yet complementary routes: the linguistic test methodology (section 3) and psychological norms of valence (section 4). 3 Introducing neutral PPTs

The topic of our inquiry are PPTs that are neither clearly positive nor negative, but that, depending on the context, can be used to express something positive or negative (as the case may be). Examples of such "neutral" PPTs include adjectives such as surprising, strange, intense, excessive, as well as pairs of antonyms such simple/complex and easy/difficult. What distinguishes neutral PPTs from evaluative PPTs? Our answer will be two-fold. In this section, we put forward two novel linguistic tests that show that neutral and evaluative PPTs pattern differently in certain configurations; and in the next, we show that neutral and evaluative PPTs tend to score differently with respect to the valence ratings provided by psychological norms. By putting those two approaches together, we hope to set a precedent in the research on PPTs.

\subsection{Two linguistic tests to identify neutral PPTs}

In line with the methodology adopted in section 2, we propose two tests that function as diagnostics to make a distinction that has been neglected in prior work -- namely the distinction between evaluative and neutral PPTs. (The tests should be applicable to other adjectives as well, but we will confine our attention to PPTs.)

\footnotetext{
${ }^{9}$ The idea that judgments of taste are inherently evaluative may be traced to a long-standing tradition of expressivism in philosophy (for a recent survey, see Soria Ruiz, Cepollaro \& Stojanovic 2021). While this tradition has been developed in metaethics, and most forcefully applied to moral (but also aesthetic) judgments, its application to PPTs is straightforward. To judge a cake to be delicious, or an activity to be fun, is to express a PRO attitude; to judge a soup to be insipid, or a game to be boring, is to express a CON attitude. According to certain authors, it is precisely this clash of attitudes that drives the intuition of disagreement (eg Marques 2015, López de Sa (this volume)). This being said, the expressivist literature also recognizes that not all such judgments need to be necessarily either positive or negative. That is to say, in addition to PRO attitude and CON attitude, there are attitudes of indifference (see Dreier 2006). We will briefly return to this idea in section 5 , in relation to adjectives such as 'average'.
} 


\section{The Attitude Compatibility (AC) Test:}

A sentence that ascribes a neutral PPT to something in conjunction with a positive or a negative attitude toward it sounds felicitous; by contrast, a sentence that ascribes an evaluative PPT to something in conjunction with a mismatching attitude toward it tends to sound infelicitous.

(5a) ?? This game is fun and I don't like it.

(5b) ?? This game is boring and I like it.

(5c) $\checkmark$ This game is surprising and I (don't) like it.

$\checkmark$ This game is intense and I (don't) like it.

\section{The GOOD/BAD WAY Test:}

Neutral PPTs sound felicitous when modified with the phrases "in a good way" and "in a bad way"; in contrast, evaluative PPTs tend to sound infelicitous in this configuration, as illustrated by the following examples:

(6a) ?? This game is fun in a good way.

(6b) ?? This game is fun in a bad way.

(6c) ?? This game is boring in a good way.

(6d) ?? This game is boring in a bad way.

(6e) $\checkmark$ This game is surprising in a good way.

(6f) $\checkmark$ This game is surprising in a bad way.

(6g) $\checkmark$ This game is intense in a good/bad way.

Like the tests proposed to identify PPTs, these tests that we propose to distinguish between evaluative and neutral PPTs are not without problems, so let us try to forestall some of the possible worries.

As previously noted, judging sentences for felicity out of context may seem problematic. Recall, however, that the tests do not mean that for a neutral predicate, the sentence is felicitous in any context whatsoever while for an evaluative predicate, there is no context in which it is felicitous. Such an interpretation is too strong, in both directions. In particular, with enough creativity, one can always come up with a context in which even predicates such as 'fun' and 'boring' may be felicitously modified with phrases "in a good/bad way" and asserted in conjunction with an attitude of mismatching valence. Rather, the idea is that for a neutral predicate, contexts in which such sentences are felicitous come straightforwardly and naturally, but not so for evaluative predicates. 
Let us look more closely at each test. For the AC Test, we have opted for a formulation with the verb "like". ${ }^{10}$ The advantage of this choice is that 'liking' is a very natural way of expressing one's positive assessment of objects of taste; and indeed, this is how most of the literature on disagreement about taste does it. But there is a disadvantage, too. Note that one positive feature is not enough to make the overall assessment of an object positive and warrant that one shall like it. Similarly, one negative feature is not enough to warrant that one shall not like it either. What is more, a person may still like something that they recognize as deserving a negative assessment and, vice versa, dislike something that they recognize as positive.

Because of this subtle relationship between valence and likeability, we should expect that even in the case of evaluative PPTs, one can consistently apply a positive adjective to an object while denying that one likes the object, or apply a negative adjective while affirming that one actually likes it. Nevertheless, in such cases, the speaker will indicate that there is an evaluative mismatch, for instance, by using the contrastive connective 'but' instead of 'and'. Here are two corpus-drawn examples. (In the corpus examples, the relevant adjective is underlined for ease of exposition.)

(7a) My girlfriend is boring but I truly do love her. ${ }^{11}$

(7b) Jefferson is fun but I don't like him. ${ }^{12}$

With neutral PPTs, we submit that no such contrastive particle is needed. In the next section, we will provide examples for half a dozen neutral PPTs.

Turning to the GOOD/BAD WAY Test, our claim, once again, is a relative one: We claim that neutral PPTs can occur with "in a good/bad way" more easily and naturally than evaluative PPTs. We do not claim that evaluative PPTs can never be modified with such phrases. Indeed, here are two corpus examples with the negative PPT 'boring' used with 'in a good/bad way':

(8a) Ted was an accountant, and he acted like I expected an accountant to act, which doesn't mean that he was boring, but... Well, let's just say that he was more adult than any of my other friends. More mature. More... well, yes, boring, but boring in a good way. (The Night We Met, Rob Byrnes, p. 2; author's italics.)

(8b) Not really exciting, boring -in a bad way (yes boring can sometimes be a good thing). Same effect, same location during the whole film. ${ }^{13}$

\footnotetext{
${ }^{10}$ It is worth noting that, in some contexts, in the phrase 'and I (don't) like it', 'it' can be interpreted as referring to an entire proposition. However, in the present discussion we focus on the non-propositional reading where the attitude is towards the object itself, e.g. the game in (5).

${ }^{11} \mathrm{https}$ ///www.quora.com/My-girlfriend-is-boring-but-I-truly-do-love-her-How-do-I-bring-out-the-fun-in-ourrelationship

12 https://discourse.disneyheroesgame.com/t/elimination-game/994504/835;

${ }^{13}$ Review of the Oscar De La Renta 2011 fashion film; https://popseeculdotcom.wordpress.com/2011/07/16/fashion-films/
} 
In the first example, we see that the author truly needs to build up a context in which "boring in a good way" makes sense. In the second, the author is aware that "boring in a bad way" sounds odd, since to say about something bad that it is so "in a bad way" is redundant. This is why they explicitly deny the redundancy implicated by the adjective's meaning by adding that "boring can sometimes be a good thing". These examples thus fit with our claim that while neutral PPTs can easily occur with 'in a good/bad way' (as discussed more below), evaluative PPTs can only occur with these phrases when extra contextual support and explanation is provided.

Another potential worry with this test is that "in a good/bad way" can be used to cancel an implicature, as the following corpus-drawn examples illustrate:

(9) The meal was excellent (tapas plate and paella), the service was great, the wine was cheap (in a good way!), but forget all of that: try the dessert! ${ }^{14}$

(10) Nisemonogatari has proven itself to be a truly gripping and overly satisfying (in a good way) anime. $^{15}$

To say of a wine that it is cheap invites the inference that it is not good; by adding "in a good way", in parentheses and with an exclamation mark, the speaker of (9) successfully blocks this inference. Thus predicates that are not even PPTs, such as 'cheap/expensive', can felicitously combine with the phrase "in a good/bad way" when it is used in this way. What is more, even evaluative predicates can do so, as (10) illustrates. To say of an object, or an experience, that it is "satisfying" will often implicate that it is not particularly good - the implicature at stake can be seen as a scalar implicature: by placing an object at the level of 'satisfying', the speaker implicates that it does not reach any stronger level (such as 'good', 'very good', 'excellent' or 'outstanding'). Fortunately, implicature-cancelling uses of the phrase are often easy to detect: in writing, by typography (parentheses, exclamation marks, preceded by three dots or a hyphen), in speech, by prosody, and in general, when they are preceded by contrastive connectives such as 'but'. ${ }^{16}$ Neutral PPTs, on the other hand, occur with the phrase 'in a good/bad way' without any kind of implicature-cancelling meaning. Thus, when applying the GOOD/BAD WAY Test as a diagnostics for neutral PPTs, we need to be careful to exclude implicature-cancelling uses.

Despite these and other worries, ${ }^{17}$ we maintain that the GOOD/BAD WAY Test provides an efficient tool to categorize neutral PPTs. Once again, though, one needs to keep in mind that for an expression to pass the test, it is not enough to simply come up with a context in which it sounds good. Rather, what characterizes neutral PPTs is that they can be very easily and naturally modified by "in a good/bad way."

\footnotetext{
${ }^{14}$ Review of Tres Leches Eatery; https://www.groupon.com/biz/jacksonville/tres-leches-1

${ }^{15} \mathrm{https}$ ://korabikka.wordpress.com/2012/03/21/nisemonogatari-11-review-final/

${ }^{16}$ For information, in a corpus search performed on the COCA corpus, approximately one in every six occurrences of "in a good way" is preceded by "but".

${ }^{17}$ Yet another worry is that in English, the expression "in a good/bad way" also has a metalinguistic use, meaning "in the good/bad sense of the word". An example is the English title of the quebecois movie "Charlotte a du fun", which is "Slut in a good way" as a translation of the French phrase, used in the movie, "salope dans le bon sens du terme". To detect such uses, one may run the test in a language free of such ambiguity,
} 


\subsection{What is in the class of neutral PPTs? Data from linguistic tests and corpora}

Now that the linguistic tests are in place, let us look at the PPTs themselves that, we think, qualify as neutral. Let us stress at the outset that the set of neutral adjectives considered here is not exhaustive. Rather, we will focus on some paradigmatic adjectives. What is more, we do not claim that the divide between neutral and evaluative PPTs is sharp. There may well be borderline cases; that is, adjectives for which it may be debated whether they are more like the (clearly) evaluative or the (clearly) neutral ones. The flexibility in deciding what to classify as evaluative rather than neutral follows from the nature of the tests and norms that we use in classification, and we take this to be a strength of our approach. ${ }^{18}$

We have grouped the neutral PPTs into three subclasses, as follows:

\section{The difficulty class:}

basic, complex, complicated, easy, difficult, formidable, intricate, obvious, simple, sophisticated, straightforward, uncomplicated

\section{The excess class:}

excessive, extraordinary, extravagant, flashy, grandiose, intense, lavish, ostentatious, provocative, remarkable

\section{The surprise class:}

amazing, astonishing, bizarre, interesting, intriguing, odd, peculiar, strange, surprising, unexpected, unusual, weird

We take this three-way classification to be rather intuitive, but nothing important hinges on it. We do not take these adjectives or subclasses to exhaust the class of neutral adjectives. ${ }^{19}$ In

\footnotetext{
${ }^{18}$ For instance, 'entertaining' and 'intimidating' are such. 'Entertaining' has a positive valence, but less strongly so than 'fun', and because of that, it patterns more easily with the two tests. 'Intimidating' has a negative valence, but because the negative experience that it reports is often based on positive features (eg a very smart person may be intimidating because of that) it can trigger a positive evaluation; at least, much more easily than 'boring' or 'disgusting'.

${ }^{19}$ Although we do not focus on adjectives of gustatory taste, it seems that there may also be neutral PPTs used in the gustatory domain, for example spicy and fruity (though the adjective tasty is not neutral). Corpus examples show that spicy and fruity easily pass the Attitude Compatibility test and the GOOD/BAD WAY test. We include some examples below. We leave more detailed investigation of the neutrality of these gustatory expressions for future work.

(i) Oh, that is fruity and I like it [writing about beer] https://untappd.com/b/grand-river-brewery-blancstare/2462300

(ii) Blue Oak's spicy chicken sandwich is only available on Tuesdays, so plan accordingly. The name doesn't lie: this one is so spicy! And I like it. https://antigravitymagazine.com/column/reality-bites-24/

(iii) They are seasoned just perfectly and nothing was spicy in a bad way https://www.tripadvisor.com/ShowUserReviews-g37209-d1094813-r679170047-

Fogo de Chao Brazilian Steakhouse-Indianapolis Indiana.html

(iv) Our Belgian is super fruity, in a good way. We don't know why. [writing about beer]

https://www.reddit.com/r/Homebrewing/comments/2z773h/our belgian is super fruity in a good way we dont/
} 
fact, in section 5, we will introduce and discuss yet another subclass: what we call middling adjectives. In the rest of this section, we describe each subclass, and in the next section, we apply the two new tests -- the Attitude Compatibility Test and the GOOD/BAD WAY test -- to some representative members of each class, to show how the tests can be used to diagnose these adjectives as neutral.

In the difficulty class, we find PPTs related to the perceived difficulty or complexity of things. In the antonym pairs, such as difficult/easy and complex/simple, the first member often seems less positive than the second. Nevertheless, the reason why we consider these adjectives to be neutral, rather than evaluative, is that their valence is highly context dependent: if we are talking, say, of one's personal situation, then difficult and complex are worse than easy and simple; but if we are talking about games and puzzles, then it is usually the other way round. ${ }^{20}$

In the excess class, as its name suggests, we find adjectives related to excess - or, to the extent that they are PPTs, to perceived excess and, more generally, deviation from a standard. Some deviations are good, some are bad. This intuitively explains why the adjectives in this class can be used both with a positive and a negative valence. ${ }^{21}$

In the surprise class, as the name suggests, we find adjectives that report surprise and other experiences of its ilk. Such experiences can be positive or negative. It is no coincidence that in the literature on emotions, surprise is a controversial topic. While all the other basic emotions are either clearly positive (e.g. happiness) or negative (e.g. fear, sadness, anger), surprise can be both.

In the remainder of this section, we will run a selection of these PPTs through the two tests from the previous section. More precisely, we will provide naturally occurring examples from corpora. In section 4.3., we will return to these adjectives, and provide further evidence showing that they are importantly different from evaluative PPTs.

\subsubsection{The context sensitive class: Difficult and easy}

Our first example shows that 'difficult', despite having a prima facie negative connotation, patterns well in positive evaluation both with the AC Test (ex.11a) and with the GOOD/BAD WAY Test (ex.11b):

(11a) The workshop was fun, challenging and difficult in a good way. We loved it. ${ }^{22}$

\footnotetext{
${ }^{20}$ In the present paper, we leave aside the question of which mechanisms, semantic and pragmatic, determine the valence that a neutral PPT has on a specific occasion of use. This question was partly addressed in Stojanovic (2016) in relation to the adjective 'intense'.

${ }^{21}$ There is a philosophical tradition, originating with Aristotle, that holds that excess is bad per se. On a linguistic level, the modifier 'too' (as in "too easy"/"too difficult"), which indicates excess, appears indeed to always trigger a negative evaluation (see Bylinina 2014, Vayrynen 2013: ch. 7). Nevertheless, when we look at value scales that range from more negative to more positive, exceedance from mean value can clearly go in either direction.

22 https://www.sebright.hackney.sch.uk/maths/the-happy-puzzle-company
} 
There are thousands of similar corpus examples, most often related to games. But even with respect to games, difficult can be bad, as the following example illustrates:

(11b) If you don't make it easy to get a reasonable selection of tiles out for the players to choose from, it becomes frustratingly difficult (in a bad way) to build your ship. ${ }^{23}$

To complete the picture, here is 'difficult' passing the AC Test in the other direction (ex.11c), as well as examples displaying 'easy' with both tests (ex.12a,b,c).

(11c) Mistakes happen. We f*ck up. It's not the end of the world. But it is difficult, and I don't like it. $^{24}$

(12a) It was very easy, in a good way. ${ }^{25}$

(12b) Fun read, it was easy and I like it a lot! ${ }^{26}$

(12c) It was easy, agreed. But (...) I don't see the problem in giving our younger members something to look at, without putting them down by the "it's easy, i don't like it" phrase I seem to hear so often. ${ }^{27}$

\subsubsection{The excess class: Excessive and intense}

'Excessive' with the AC Test:

(13a) Her pout is excessive and I like it. ${ }^{28}$

(13b) It's excessive and I hate it. ${ }^{29}$

'Excessive' with the GOOD/BAD WAY Test:

(13c) The gastropub, widely known for their excessive (in a good way) beer list and perhaps not as widely known top notch service, opened its doors to bar goers on Friday, December 16 th. $^{30}$

${ }^{23}$ https://boardgamegeek.com/thread/939678/galaxy-trucker-tile-drafting-ship-construction-var

${ }^{24} \mathrm{https}$ ://www.katetoon.com/is-speaking-at-international-events-worth-the-faff/

${ }^{25}$ Said about a video game called Wired. https://www.engineering.com/story/wired-a-video-game-tospark-interest-in-engineering

${ }^{26}$ Said about a mystery teaser.

https://www.braingle.com/brainteasers/teaser.php?id=29093\&op=0\&comm=1

Note that the phrase "it is easy and I like it" is very often found in relation to recipes, but there, the object arguably shifts - the preparation is easy, but the output is what is being liked.

${ }^{27} \mathrm{https}$ ://www.braingle.com/brainteasers/teaser.php?op=2\&id=15922\&comm=1

${ }^{28} \mathrm{https}$ ://bluefifthreview.wordpress.com/2012/09/19/the-blue-collection-2-music-12-19-summer-2012/

${ }^{29} \mathrm{http}: / /$ www.twixtmynethers.com/2018/06/22/the-don/

Larger context: "You could hypothetically plug this toy in on one floor and masturbate on the next, if that's what you're into I guess. For some, this may sound awesome, but for me it's just kind of an annoyance. I don't need this much cord. It's excessive and I hate it."

${ }^{30} \mathrm{https}$ ://stepoutbuffalo.com/griffon-gastropub-opens-g3-in-east-aurora/ 
(13d) The games feel excessive in a bad way now. Over- or under-designed, the dialogue is definitely not as great anymore. . ${ }^{31}$

'Intense' with the AC Test:

(14a) The Maddening is pretty intense and I like it. ${ }^{32}$

(14b) His stare was intense and I didn't like it. ${ }^{33}$

'Intense' with the GOOD/BAD WAY Test:

(14c) He was very bright, intense in a good way. ${ }^{34}$

(14d) Being away from Diana at one part of the book hurt him so bad and made him super moody and blood-rushy - it was intense in a bad way. ${ }^{35}$

\subsubsection{The surprise class: Strange and surprising}

'Strange' with the AC Test:

(15a) Religious Overdose, from Northampton, were the first band to send me a tape. It was strange and I liked it. ${ }^{36}$

(15b) The way this book is written is very strange and I don't like it. ${ }^{37}$

'Strange' with the GOOD/BAD WAY Test:

(15c) Everything about this week's episode of WWE SmackDown was strange. The good parts were strange in a good way and the bad parts were strange in a bad way, in my opinion at least. $^{38}$

(15d) Because you are strange in a good way, there is always room in this world for you. ${ }^{39}$

'Surprising' with the AC Test:

(16a) This book is interesting and a bit surprising and I like it! $!^{40}$

${ }^{31} \mathrm{https}$ //www.siliconera.com/tales-rays-shares-latest-key-visual-showing-original-characters-others/

32 https://echoesanddust.com/2020/03/bruxa-maria-the-maddening/

${ }^{33}$ Lauren Nicolle Taylor, The Woodlands Series Boxed Set, ch. 39. FantasticFiction, 2017.

34 lan Fisher, Do Threads of Five Lives Lead to One Serial Killer? New York Times 1993 (source: COCA).

${ }^{35}$ https://blattzirkus.wordpress.com/2019/01/14/review-the-book-of-life-by-deborah-harkness-a-discoveryof-witches-3/

${ }^{36}$ David Barker, cover of the album Glass Hymnbook (1980-82, released in 2017).

37 https://www.amazon.com/product-reviews/B00B63M468

${ }^{38} \mathrm{https}$ ://www.sportskeeda.com/wwe/best-and-worst-of-wwe-smackdown-top-superstar-misses-the-showextremely-strange-pairing

${ }^{39}$ Lyrics of the song "Strange in a good way" by Auna Sims, album Evidence, 2017.

${ }^{40} \mathrm{https}: / /$ www.goodreads.com/book/show/55200690-downeast 
(16b) The result is surprising: I don't like it. ${ }^{41}$

Turning to the GOOD/BAD WAY Test, the expressions "surprising in a good way" and "surprising in a bad way", as well as the related past participle forms, "surprised in a good/bad way", abound on websites and platforms that provide reviews. Only on TripAdvisor, we find (at least) five reviews whose title is "surprising in a good way", several more with "bad", and many more occurrences of both phrases in the reviews themselves.

\section{Neutral predicates: Data from psychological norms}

There is a long tradition of research in cognitive psychology regarding effects of valence on various aspects of human cognition and information processing, including attention and memory (e.g. Pratto \& John 1991, Ortony et al. 1983, Unkelbach et al. 2008, Alves et al., 2015). Thanks to the decades-long research interest in valence, there exist large-scale datasets ('norms') that report people's valence judgments for large sets of words in different languages. In this section, we make use of one of the most recent and largest norms, collected by Warriner et al. (2013) for 13,915 English words, to explore the valence ratings given to the adjectives that we posit are neutral PPTs. Warriner et al. asked native English speakers to rate words on a 9-point scale ranging from unhappy (1) to happy (9) -- thus, the higher the number, the more positively valenced the word. ${ }^{42}$ Thus, the scale reflects the "valence (or pleasantness) of the emotions invoked by a word" (Warriner et al. 2013:1192). This is, intuitively, a broad and emotion-based scale, in the sense that multiple factors/dimensions can contribute to whether something makes a person feel happy or unhappy. We view this as an advantage, given that we are interested in the broad concept of valence. Indeed, the Attitude Compatibility Test and the GOOD/BAD WAY Test are also broad -- in other words, they do not target a particular dimension (e.g. worth or unworth) but instead aim to tap into a broader notion of valence. ${ }^{43}$

\footnotetext{
${ }^{41}$ In a forum about the Egnater Renegade Amplifier; the larger context is: "I checked the Bias: it was perfect for the 5881's but just a bit cold for the EL34's (62MV), so I raised it to 72MV. The result is surprising: I don't like it", followed by a confounded face emoji.https://www.rigtalk.com/forum/threads/swapping-tubes-renegade.114859/

42 In the norming study, the words were presented in isolation, not in sentences or larger contexts. This allowed the researchers to ensure that participants' ratings were only based on the semantics of each individual word being tested, rather than the semantic or pragmatic contribution of the rest of the sentence. In our view, the fact that the norms were collected on the basis of words in isolation is not incompatible with the possibility of a word's precise valence being potentially influenced by context (for related work on the distinction between negative words in isolation and in different contexts, see also Cepollaro et al. 2019).

${ }^{43}$ Of course, we are aware that affective valence and (if we may call it so) axiological valence need not always align, especially in the moral and (to a lesser extent) aesthetic sphere. For instance, a person can feel very happy at the idea of leaving a restaurant without paying for their meal, but at the same time recognize that such an action is morally bad. Similarly, a person can value a work of art very highly, such as Picasso's Guernica or Delacroix's Massacre at Chios, even if, because of their subject, such works are unlikely to elicit happiness. For a related discussion, see Stojanovic (to appear).
} 
The valence ratings are the main focus of this section, but we also report the arousal ratings for each of the neutral PPTs that we discuss in this paper. Arousal is defined as "the intensity of emotion provoked by a stimulus" (Warriner et al 2013:1191). In addition to valence ratings, Warriner et al. also asked native English speakers to rate words on a 9-point scale ranging from calm (1) to excited (9) for arousal. (They also investigated a third dimension, which they term 'dominance', which is not relevant to the present discussion.)

To provide a sense of the ratings, here are some examples of valence and arousal ratings for some non-neutral PPTs: tasty valence 6.89, arousal 5.28; fun valence 8.37, arousal 6.32; boring valence 2.71 , arousal 2.85 ; frightening valence 2.58 , arousal 4.73 .

It is worth pointing out that a word can have a high positive valence rating while also having a low arousal rating (e.g. calm is rated 6.89 out of 9 for valence and 1.67 out of 9 for arousal). Thus, a low arousal rating does not mean that a word does not elicit a valenced response; arousal simply reflects the emotional intensity of the response.

One of the reasons for investigating arousal ratings will become clear in section 5: Arousal ratings play a key role in our comparison of neutral PPTs to what we call 'middling' adjectives. We suggest that among the adjectives that are neither (clearly) positive nor negative, there is a difference between (i) what we call neutral PPTs, which we suggest are underspecified for their valence but can, depending on the context, be interpreted as expressing an evaluation, and (ii) what we call middling adjectives, whose function is to place an object toward the middle of the scale (e.g. average, mediocre). In our view, therefore, middling adjectives are, crucially, not underspecified for valence. As we will show in section 5 , this distinction is reflected by the fact that middling adjectives score low(er) on "arousal", which we think is because such adjectives typically, unlike the other neutral PPTs, do not convey any emotional response. We postpone a more detailed discussion of this class of middling adjectives, and its relation to neutral PPTs, until section 5 .

In addition to differentiating neutral PPTs and middling adjectives, arousal ratings provide another window into the semantics of the adjectives under discussion and, as we will see in the following sections, reveal some asymmetries between the three subtypes of neutral adjectives that we consider in this paper.

\subsection{A closer look at each class}

Figures 1, 2 and 3 show the valence and arousal ratings for neutral PPTs that we suggest are in (i) the difficulty class, (ii) the excess class and (iii) the surprise class, respectively. The adjectives are ordered on the y-axis with valence increasing from left to right. As we mentioned earlier, the adjectives that we suggest for each class are not intended to be an exhaustive list.

Recall that the higher the valence rating, the more positive the adjective was rated; the higher the arousal rating, the more intense the emotion elicited by the adjective. Because the scale goes from 1 to 9 , the midpoint is 5 . 
The twelve adjectives that we grouped into the difficulty class (Figure 1) have an average valence rating of 5.56 out of 9 (range 3.78-7.47), and an average arousal rating of 4.09 out of 9 (range 2.71-5.75). Of the three classes, this is the only one that contains antonyms, such as difficult/easy, complex/simple, complicated/uncomplicated. Indeed, when we look at the valence ratings, it is clear that the highest (easy, simple, uncomplicated) and lowest (difficult, complicated, complex) valence ratings come from opposing members of these antonym pairs.

However, we note that even if these words may appear to be lexically valenced, their valence ratings are still near 5 , the midpoint of the scale (see also section 4.2). Thus, in our view they still deserve to be considered as neutral PPTs given how they fare in terms of the Attitude Compatibility test and the GOOD/BAD WAY tests (see Sections 3.2 and 3.3 above).

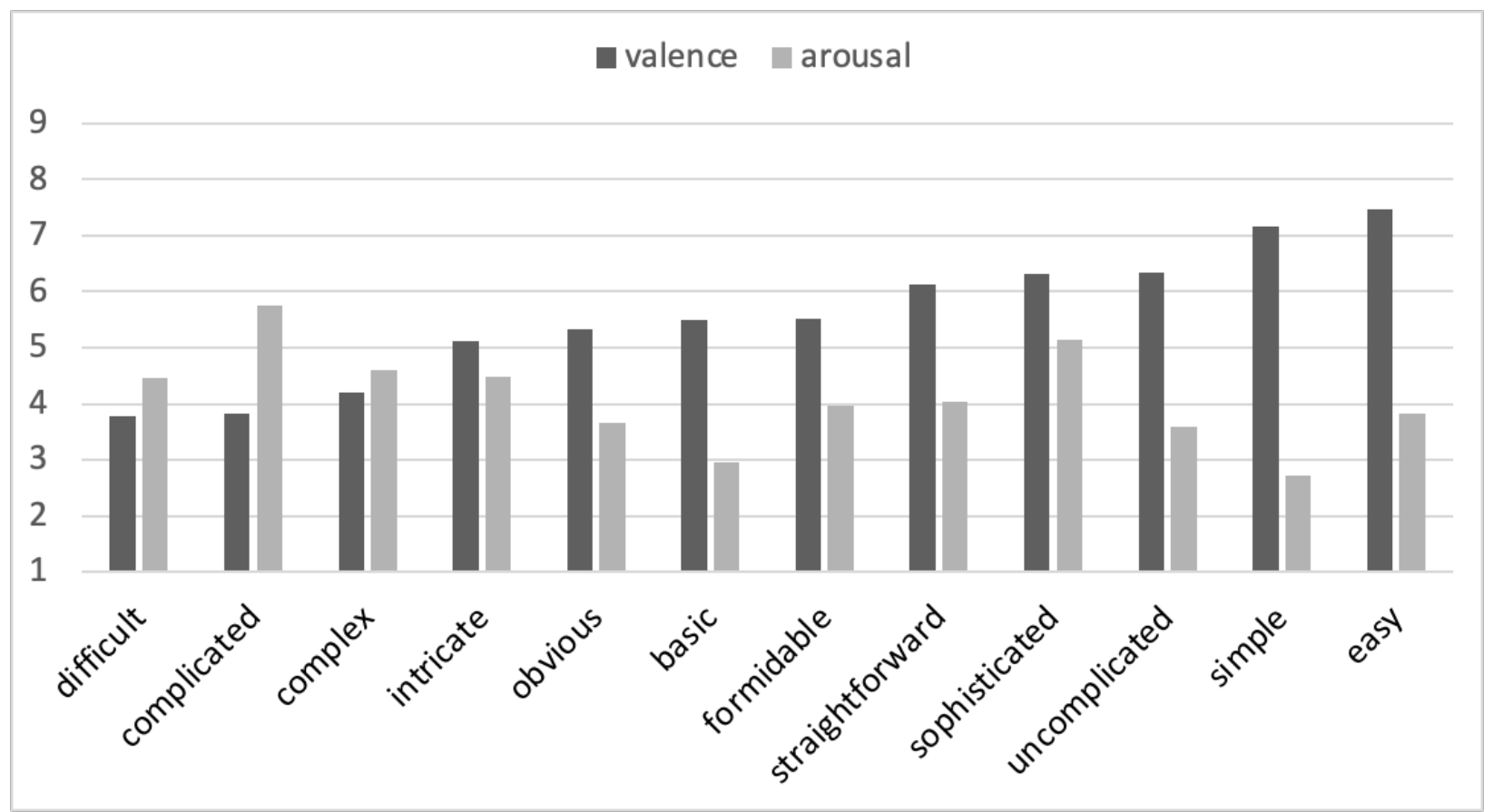

Figure 1. Difficulty class (Average valence: 5.56 , average arousal: 4.09 . Range for valence: 3.78-7.47, range for arousal: 2.71-5.75)

The ten adjectives that we grouped into the excess class (Figure 2) have an average valence rating of 5.84 out of 9 (range 4.37-7.45), and an average arousal rating of 5.07 out of 9 (range 3.73-6.6). The twelve adjectives that we grouped into the surprise class (Figure 3) have an average valence rating of 5.69 out of 9 (range 4.41-7.72), and an average arousal rating of 4.86 out of 9 (range 3.5-6.05). Thus, broadly speaking, all three classes have average valence and average arousal scores near the midpoint of the scale -- in line with our characterization of them as neutral adjectives.

In all three classes, valence ratings are numerically higher than arousal ratings. Paired t-tests show that this difference is significant in the context sensitive class and the surprise class, but 
not in the excess class (Difficulty class: $t(11)=2.576, p<0.02$; Surprise class: $t(11)=3.772$, $p<0.01$; Excess class: $t(9)=1.609, p=0.142)$. The lack of a clear valence-arousal difference in the excess class indicates that adjectives in this class tend to have more comparable levels of valence and arousal than those in the other two subclasses, which may be related to the emotional intensity (arousal) associated with exceeding a standard.

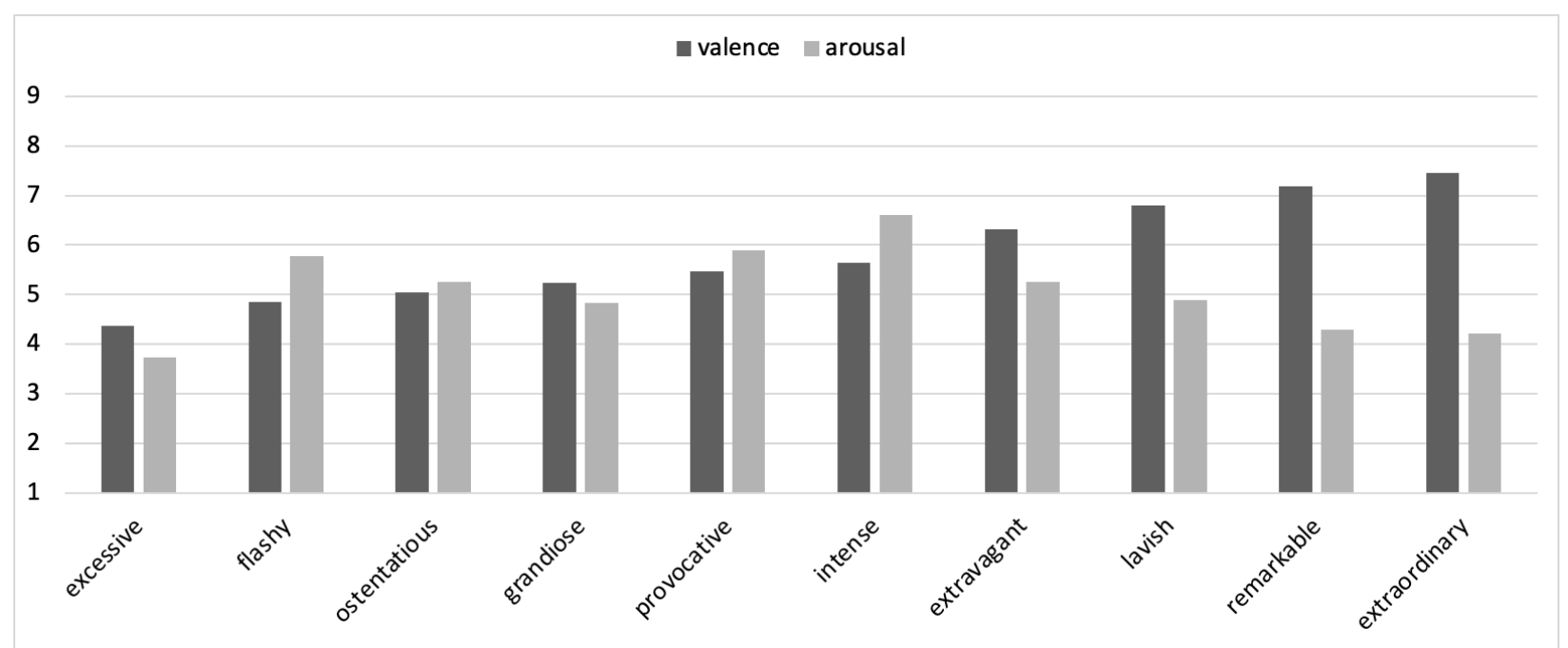

Figure 2. Excess class (Average valence: 5.84, average arousal: 5.07. Range for valence: 4.377.45 , range for arousal: $3.73-6.6$ )

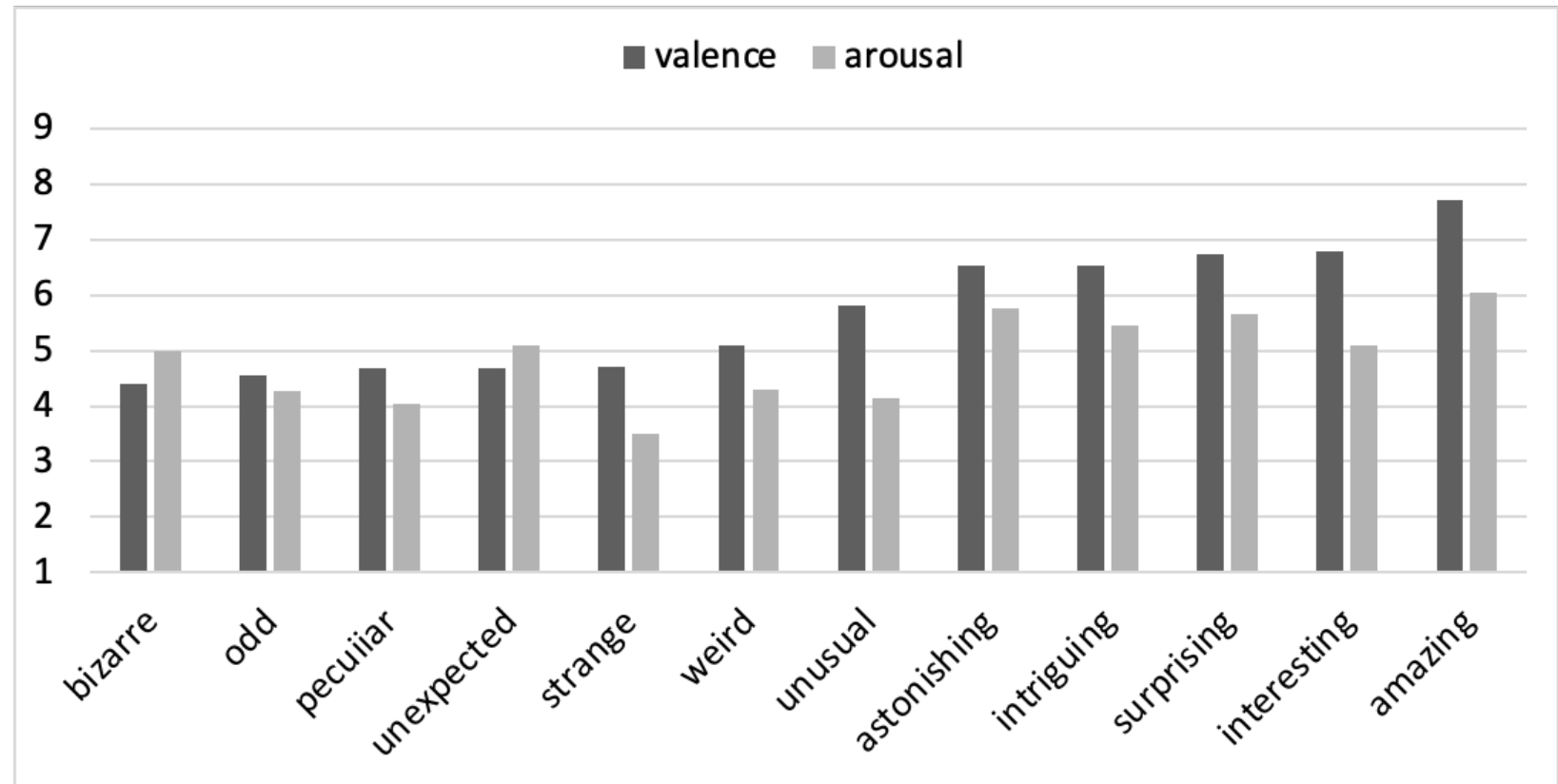

Figure 3. Surprise class (Average valence: 5.69 , average arousal: 4.86 . Range for valence: 4.41-7.72, range for arousal: $3.5-6.05$ ) 


\subsection{Comparing the three classes to each other}

When we compare the valence ratings between the three classes of neutral adjectives, there are no statistically significant differences. In other words, the difficulty class, the excess class and the surprise class have comparable valence ratings. This shows that there are no significant differences in the level of 'neutrality' of the three subclasses of neutral PPTs that we have been discussing.

In our view, this supports our classification of all three groupings as subclasses under the broader umbrella of neutral adjectives.

Once we turn to the arousal ratings, we find that arousal ratings for the context sensitive class are significantly lower than the other two classes (unpaired t-tests: Difficult vs. Excess: $\mathrm{t}(20)=2.652, \mathrm{p}<0.02$; Difficult vs Surprise $\mathrm{t}(22)=2.272, \mathrm{p}<0.05$; Excess vs. Surprise $\mathrm{t}(20)=0.592$, $\mathrm{p}=0.561$ ). This presumably stems from the fact that both 'exceeding a standard' and 'being surprised' involve more emotional intensity than -- on average -- the adjectives from the difficulty class.

\section{5 'Middling' Adjectives}

In this section, we introduce yet another subclass of adjectives that are neither clearly positive nor clearly negative, but which we think are interestingly different from the neutral PPTs that we have discussed so far. We call them "middling" adjectives, because their function is, in a nutshell, to place an object somewhere near the middle of a corresponding scale. ${ }^{44}$

\section{The middling class:}

average, commonplace, habitual, humdrum, mediocre, moderate, mundane, normal, ordinary, plain, regular, routine, standard, typical

The neutral PPTs that we have previously discussed, be they in the difficulty class, the excess class, or the surprise class, are such that most often, they convey an evaluation -- however, whether the evaluation is positive or negative depends on the context. Middling adjectives, on the other hand, may be said to systematically convey a "neutral" evaluation -- that is, to convey that a given object deserves neither a positive nor a negative evaluation. ${ }^{45}$

\footnotetext{
${ }^{44}$ It is worth keeping in mind that middling adjectives may be felt, especially in some contexts, to be somewhat negative. For example, if a recommender describes an applicant as 'average' in a recommendation letter, this is perceived to be a negative recommendation. Even though, strictly speaking, 'average' picks out a value 'in the middle' of a scale, in many contexts this is felt to be negative because a higher value is preferred. Thus, we suggest that the negative connotation may be a pragmatic, contextual inference due to Gricean reasoning about other adjectives that could have been used instead (e.g. 'outstanding' and so on). In the norms (without context), terms like 'mediocre' (valence 4.43) and 'average' (valence 4.89 ) receive ratings very close to 5 , the scale midpoint.

45 If we help ourselves to the expressivist way of thinking (see footnote 9), we could say that just as judging something to be "good" invites a PRO attitude and something to be "bad" a CON attitude, judging
} 
In light of this, we regard the two tests proposed above, the Attitude Compatibility test and GOOD/BAD WAY test as not meaningful or well-suited for middling adjectives. This is because the function of middling adjectives -- to place an object in the middle of a scale -- clashes with the AC and GOOD/BAD WAY tests, which indicate a positive or negative evaluation. Thus, although the tests are well-suited for neutral adjectives, which are underspecified for their valence and, depending on the context, can give rise to a positive, a negative, or an ambivalent evaluation (or maybe no evaluation at all), the tests are not suited for adjectives such as 'average,' which we suggest are specified for a middling scale position. By definition, the aspects of meaning targeted by the tests are simply not present with the class of middling adjectives, so the tests do not apply to this class in a meaningful way. Thus, we do not use these tests as a tool to identify middling adjectives. Instead, in the following sections we show that a comparison between middling adjectives and (other) neutral PPTs from the standpoint of psychological norms reveals some intriguing differences that support the 'middling' status of this new class.

\subsection{Data from psychological norms for middling adjectives}

Figure 4 shows the valence and arousal scores for 14 adjectives that we propose are middling adjectives. Their average valence rating is 4.934 (range: $3.63-6.17$ ), and their average arousal rating is 3.116 (range: 2.29-4). Similar to what we saw for the neutral PPTs, the valence ratings for these adjectives are higher than their arousal ratings (paired t-test: $t(13)=8.407, p<0.001$ ).

However, what is striking with middling adjectives is that this asymmetry is present for every adjective that we investigated, as can be seen in the heights of the darker and lighter bars in Figure 4. Above, for the three neutral subclasses, sometimes the arousal rating is numerically higher than the valence rating for a particular adjective, and sometimes it's lower. In contrast, with the middling adjectives shown in Figure 4, the arousal ratings (lighter bars) are consistently numerically lower than the valence ratings (darker bars) for every adjective. Indeed, in the next section, as we look statistically at how middling adjectives compare to the three neutral classes, it becomes clear that the arousal ratings, in particular, are much lower for middling adjectives.

something to be "average" invites an attitude of indifference. Neutral PPTs, on the other hand, seldom invite indifference; rather, whether they invite a PRO or a CON attitude will depend on the context. 


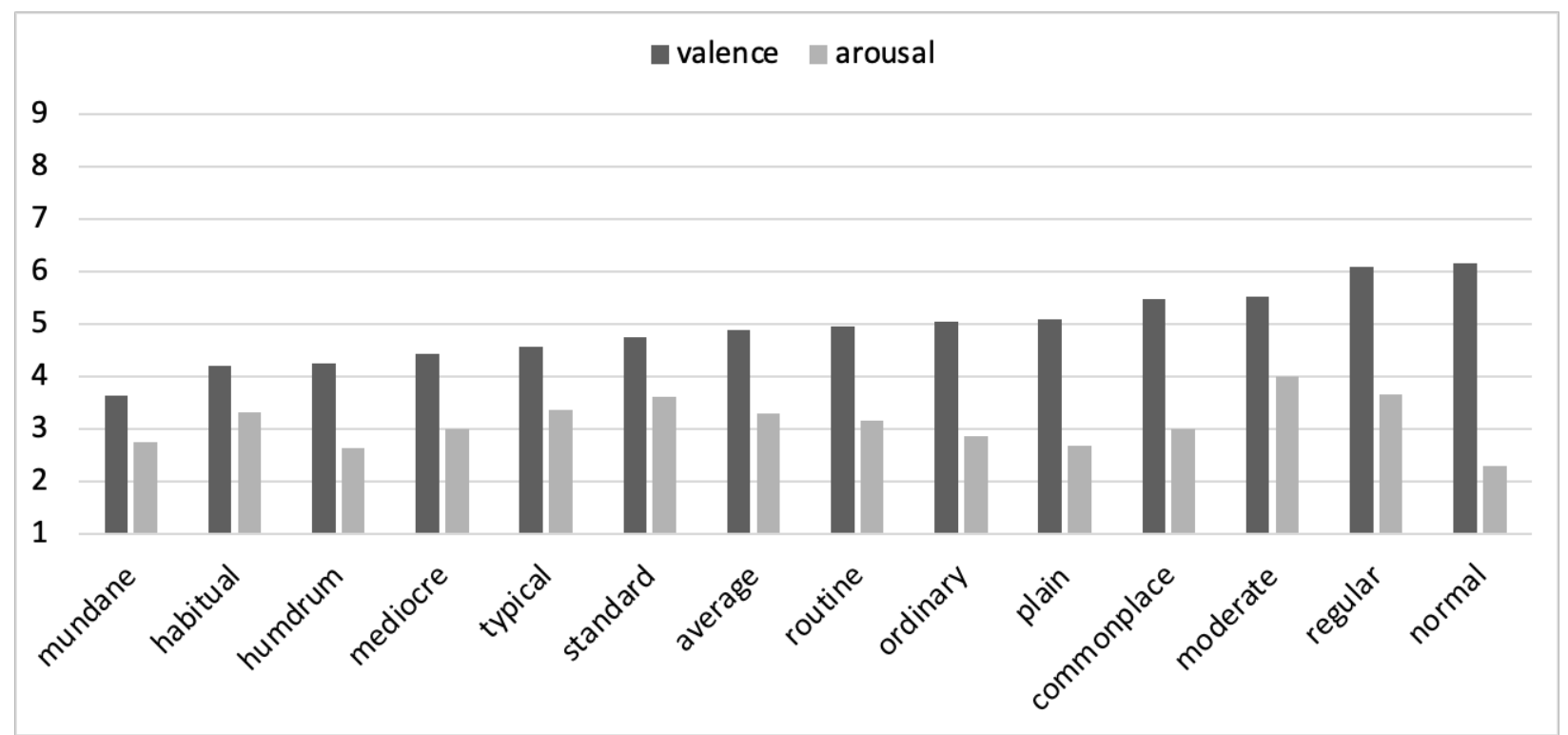

Flgure 4. Middling adjectives (Average valence: 4.934, average arousal: 3.116. Range for valence: 3.63-6.17, range for arousal: $2.29-4$ )

\subsection{Comparing middling adjectives to neutral PPTs}

In this section we show how the arousal ratings distinguish neutral and middling adjectives.

Figure 5 and Table 1 show the average valence and arousal ratings for adjectives in the neutral class (all three subclasses combined) and the middling class.

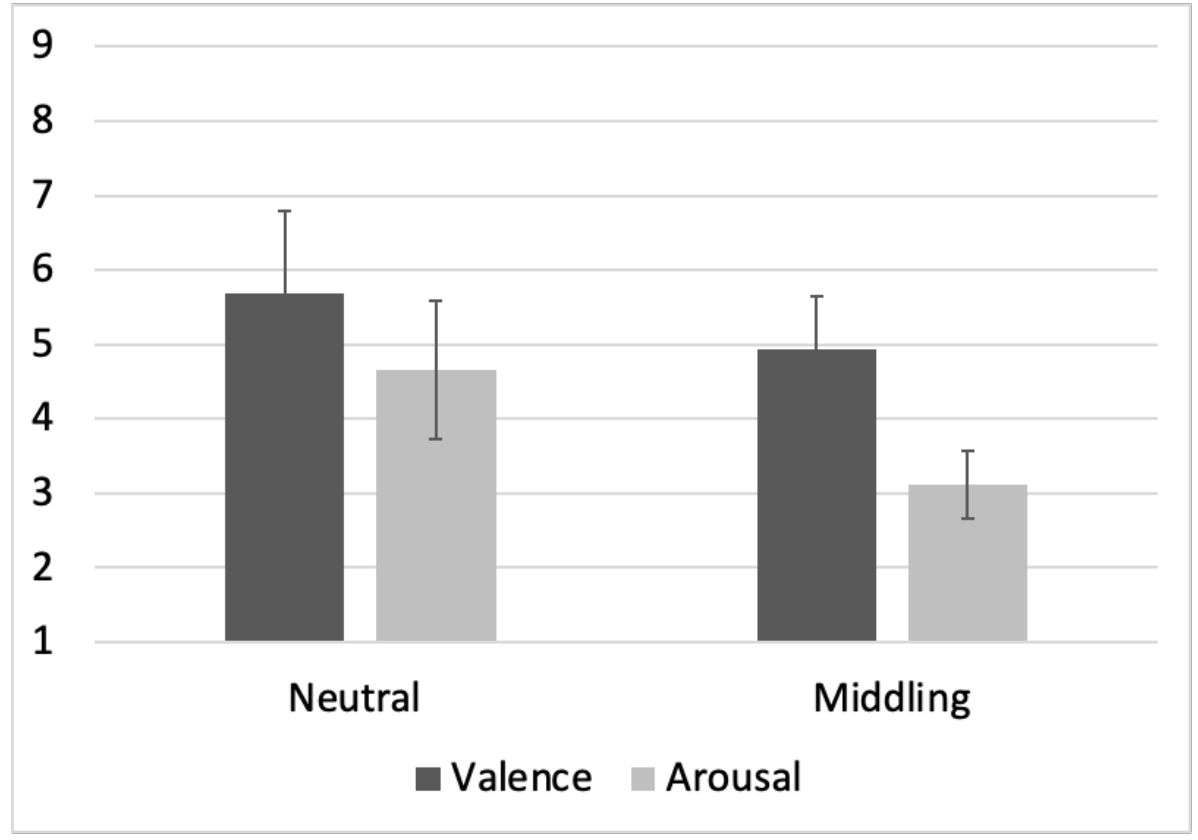

Figure 5. Average valence and arousal ratings for the 34 neutral adjectives (collapsing all three classes) and the 14 middling adjectives (error bars show $+/-1$ SD) 


\begin{tabular}{|l|l|l|}
\hline & Valence & Arousal \\
\hline Neutral & $5.686(1.106)$ & $4.656(0.921)$ \\
\hline Middling & $4.934(0.716)$ & $3.116(0.461)$ \\
\hline
\end{tabular}

Table 1. Average valence and arousal ratings (standard deviation provided in parentheses)

Statistical analyses confirm what can be seen visually in Figure 5: The valence ratings, and especially the arousal ratings, are lower for middling adjectives than neutral PPTs. First, when we compare the valence ratings between the middling adjectives and the others (using unpaired t-tests) we find the valence ratings are significantly higher in the excess class than in the middling class $(\mathrm{t}(22)=2.52, \mathrm{p}<0.02)$, marginally higher in the surprise class than in the middling class $(\mathrm{t}(24)=2.062, \mathrm{p}=0.0502)$ and numerically (i.e. not significantly) higher in the difficulty class than in the middling class $(t(24)=1.622, p=0.116)$. Thus, we see indications of a difference in valence between middling adjectives and neutral PPTs, but this is only significant with the excess subclass of neutral PPTs.

However, a much clearer asymmetry emerges between neutral PPTs and middling adjectives in the arousal ratings. When we compare the arousal ratings between the middling adjectives and the other three classes, we find that the arousal ratings are significantly higher in all three neutral PPT classes than in the middling PPT class (excess class vs. middling: $t(22)=7.174$, $\mathrm{p}<0.0001$; surprise class vs. middling: $\mathrm{t}(24)=6.948, \mathrm{p}<0.001$; difficulty class vs. middling: $t(24)=3.685, p<0.01)$.

In sum, adjectives in the middling class have significantly lower arousal ratings than each of the three neutral classes. This supports our suggestion that it is worth considering middling adjectives as a distinct group. More specifically, the finding that neutral PPTs have higher arousal ratings than middling adjectives fits with our view that (i) neutral PPTs are underspecified for their valence but can, depending on the context, be interpreted as expressing an evaluation, while (ii) middling adjectives simply place an object toward the middle of the scale (e.g. average, mediocre) without expressing any emotional response.

\section{Conclusions}

In this paper, we have challenged the widespread, though often implicit assumption that predicates of personal taste are evaluative, i.e. that they convey either a positive or a negative assessment of the object of evaluation. We have suggested that some PPTs, e.g. 'surprising' and 'excessive' can be underspecified in terms of positive or negative valence, and thus are not evaluative. We have explored how these kinds of neutral PPTs differ from evaluative PPTs, how 
different classes of neutral PPTs differ from each other, as well as how they relate to another class that we call middling adjectives, which are neither positive nor negative (e.g. 'average').

We have approached these issues from two perspectives: First, we have proposed two new linguistic tests that can act as diagnostics to identify neutral PPTs, and we have provided corpus evidence complementing the tests. Second, we have analyzed the valence and arousal ratings of the adjectives under consideration using pre-existing psychological forms (Warriner et al. 2013).

This investigation yields a diverse and nuanced class of neutral PPTs, which we suggest can be broken down into at least three subclasses: the context-sensitive class (e.g. 'difficult', 'easy'), the excess class (e.g. 'ostentatious', 'intense') and the surprise class (e.g. 'surprising,' strange'). We have also explored a fourth class, middling adjectives, whose status as PPTs is less clear (e.g. 'mediocre', 'basic'). This is not intended to be an exhaustive classification, nor are the adjectives that we have analyzed intended to be regarded as exhaustive lists. Rather, we regard the adjectives simply as paradigmatic examples of the different types, and one of our aims is to broaden the kinds of adjectives that are included in the discussions of judgements of personal taste.

Broadly speaking, this work contributes to our understanding of subjective adjectives by separating the notion of evaluativity (conveying a positive or negative evaluation in virtue of the expression's meaning) from the broader notion of subjectivity, and by identifying a rich class of neutral PPTs. In doing so, we also hope to have opened up new avenues for, on the one hand, linguistic research on underspecification and contextual effects on adjective interpretation, and, on the other, philosophical research on judgments of personal taste.

\section{Acknowledgments}

We are grateful to the Editors for the invitation to contribute to this volume, and, in particular, to Julia Zakkou for very helpful comments and suggestions. We would also like to thank Anouch Bourmayan, Malte Willer, Andrés Soria Ruiz, Victor Carranza and Nils Franzén, for comments on an earlier draft, as well as the audience at the LOGOS Colloquium in Barcelona, the PhiLang 2021 Conference, the Czech Society for Aesthetics, the Philosophy Colloquium at Texas Tech University, and the CCLAM Seminar at the University of Stockholm, for discussion of this and related material. At an institutional level, Isidora Stojanovic acknowledges support from grant $\mathrm{n}$. ANR-17-EURE-0017 FrontCog. Elsi Kaiser acknowledges support from the NSF, as this material is partially based upon work supported by the National Science Foundation under Grant No. 1749612 awarded to Elsi Kaiser. 


\section{References}

Alves, H., Unkelbach, C., Burghardt, J., Koch, A. S., Krüger, T., \& Becker, V. D. (2015). A density explanation of valence asymmetries in recognition memory. Memory \& Cognition, 43, 896-909.

Barker, Chris (2002). The dynamics of vagueness. Linguistic and Philosophy, 25,1-36.

Bierwisch, Manfred (1989). The Semantics of gradation, in Bierwisch, M. and Ewald Lang (eds.), Dimensional Adjectives. Berlin: Springer-Verlag, 71-261.

Brașoveanu, Adrian and Rett, Jessica (2017). Evaluativity across adjective and construction types: An experimental study. Journal of Linguistics, 54, 263-329.

Bylinina, Lisa (2014). The Grammar of Standards: Judge-Dependence, Purpose-Relativity, and Comparison Classes in Degree Constructions. LOT Dissertation Series 347. Utrecht: LOT.

Cepollaro, Bianca and Isidora Stojanovic (2016). Hybrid Evaluatives. Grazer Philosophische Studien, 93, 458-488.

Cepollaro, Bianca, Simone Sulpizio and Claudia Bianchi (2019). How bad is it to report a slur? An empirical investigation, Journal of Pragmatics, 146, 32-42

Coppock, Elizabeth (2018). Outlook-based semantics. Linguistics and Philosophy, 41 (2), 125-164

Davies, Mark. (2008-). The Corpus of Contemporary American English (COCA). Available online at https://www.english-corpora.org/coca/

Dreier, James (2006). Negation for Expressivists: A Collection of Problems with a Suggestion for their Solution. Oxford Studies in Metaethics, 1, 217-233.

Franzén, Nils (2018). Aesthetic Evaluation and First-hand Experience. Australasian Journal of Philosophy, 96 (4), 669-682.

Franzén, Nils (2020) Evaluative discourse and affective states of mind. Mind, 129, 10951126.

Gibbard, Alan (1992). Wise Choices, Apt Feelings: a Theory of Normative Judgement. Harvard University Press.

Goodwin, Geoffrey and John Darley (2008). The psychology of meta-ethics: exploring objectivism. Cognition, 106, 1339-1366.

Kaiser, Elsi (2015). Perspective-shifting and free indirect discourse. Proceedings of SALT 25, 346-372.

Kaiser, Elsi \& Rudin, Deniz. (2020). When faultless disagreement is not so faultless: What widely-held opinions can tell us about subjective adjectives. In P. Farrell (ed.), Proceedings of the Linguistic Society of America 5, 698-707.

Kaiser, Elsi \& Rudin, Deniz. (2021). Arguing with experts: Subjective disagreements on matters of taste. In Proceedings of the Annual Meeting of the Cognitive Science Society, 43. Retrieved from https://escholarship.org/uc/item/8921n58s 
Rudin, Deniz \& Kaiser, Elsi. (to appear). Connoisseurial contradictions: expertise modulates faultless disagreement. To appear in the Proceedings of SALT.

Kennedy, Christopher and Louise McNally (2005). Scale structure, degree modification and the semantics of gradable predicates. Language, 81, 345-381.

Kennedy, Christopher and Malte Willer (2016). Subjective attitudes and counterstance contingency. Proceedings of SALT 26.

Kneer, Markus (2015). Perspective in Language. PhD dissertation, École des Hautes Études en Sciences Sociales, Paris.

Kölbel, Max (2002). Truth Without Objectivity. Routledge.

Korotkova, Natasha (2016). Heterogeneity and uniformity in the evidential domain. PhD Dissertation, UCLA

Lasersohn, Peter (2005). Context dependence, disagreement, and predicates of personal taste. Linguistics and Philosophy, 28, 643-686.

López de Sa, Dan (this volume). Disagreements and disputes about matters of taste.

Marques, Teresa (2015). Disagreeing in Context. Frontiers in Psychology, 6, 257.

Moltmann, Friederike (2010). Relative Truth and the First Person, Philosophical Studies 150: 187-220.

Ninan, Dilip (2014). Taste Predicates and the acquaintance inference. Proceedings of SALT 24.

Pearson, Hazel (2013). A judge-free semantics for predicates of personal taste. Journal of Semantics, 30, 103-154.

Portner, Paul \& Aynat Rubinstein (2016). Extreme and non-extreme deontic modals. In Nate Charlow \& Matthew Chrisman (eds.), Deontic modality. Oxford: Oxford University Press. https://doi.org/10.1093/acprof:oso/978 0198717928.003.0010.

Pratto, F. \& John, O.P. (1991). Automatic vigilance: the attention grabbing power of negative social information. Journal of Personality and Social Psychology, 61, 380-391

Rudolph, Rachel (2021). Talking about appearances: the roles of evaluation and experience in disagreement. Philosophical Studies, 177, 197-217.

Ortony, A., Turner, T. J., \& Antos, S.J. (1983). A puzzle about affect and recognition memory. Journal of Experimental Psychology: Learning, Memory, \& Cognition, 9, 725-729

Sæbø, Kjell Johan (2009). Judgement ascriptions. Linguistics and Philosophy, 32, 327-352.

Sassoon, Galit W. (2013). A typology of multidimensional adjectives. Journal of Semantics, 30, 335-380.

Silk, Alex (2021). Evaluational Adjectives. Philosophy and Phenomenological Research, 102, 127-161.

Solt, Stephanie (2016). Ordering subjectivity and the relative-absolute distinction. Proceedings of Sinn und Bedeutung 20. 
Soria Ruiz, Andrés, Bianca Cepollaro and Isidora Stojanovic (2021). The Semantics and pragmatics of value judgments. In Stalmaszczyk, Piotr (Ed.) The Cambridge Handbook of the Philosophy of Language, Cambridge University Press, pp. 434-449.

Soria Ruiz, Andrés \& Federico Faroldi (2020). Moral adjectives, judge-dependency and holistic multidimensionality. Inquiry, 64, 1-30.

Soria Ruiz, Andrés \& Isidora Stojanovic (2019). On Linguistic Evidence for Expressivism. Royal Institute of Philosophy Supplement, 86,155-180.

Stephenson, Tamina (2007). Judge-Dependence, Epistemic Modals, and Predicates of Personal Taste. Linguistics and Philosophy, 30, 487-525.

Stojanovic, Isidora (2007). Talking about taste: Disagreement, implicit arguments, and relative truth. Linguistics and Philosophy, 30, 691-706.

Stojanovic, Isidora (2012). Emotional Disagreement. Dialogue, 51(1), 99-117.

Stojanovic, Isidora (2016). Expressing Aesthetic Judgments in Context. Inquiry, 59, 663-685.

Stojanovic, Isidora (2019) Disagreements about Taste vs. Disagreements about Moral Issues, American Philosophical Quarterly, 56, 29-42.

Stojanovic, Isidora (to appear). Evaluativity. In Lepore, Ernie and Una Stojnic (Eds.) The Oxford Handbook of Contemporary Philosophy of Language.

Sundell, Timothy (2011). Disagreements about taste. Philosophical Studies, 155, 267-288.

Umbach, Carla (2017). Evaluative propositions and subjective judgments. In J. van Wijnbergen-Huitink \& C. Meier (eds.) Subjective meaning. Alternatives to relativism. Berlin, de Guyter.

Umbach, Carla (2021). Evaluative Predicates beyond 'fun' and 'tasty'. In Daniel Gutzmann, Lisa Matthewson, Cecile Meier, Hotze Rullmann, Thomas Ede Zimmermann (eds.) The Wiley Blackwell Companion to Semantics.

Unkelbach, C., Fiedler, K., Bayer, M., Stegmüller, M., \& Danner, D. (2008). Why positive information is processed faster: The density hypothesis. Journal of Personality and Social Psychology, 95, 36-49.

Väyrynen, Pekka (2013). The rude, the lewd and the nasty. OUP

Warriner, A. B., Kuperman, V., \& Brysbaert, M. (2013). Norms of valence, arousal, and dominance for 13,915 English lemmas. Behavior Research Methods, 45(4).

Williams, Bernard (1985). Ethics and the Limits of Philosophy. Cambridge, MA: Harvard University Press.

Willer, Malte (to appear). Subjectivity. In Lepore, Ernie and Una Stojnic (Eds.) The Oxford Handbook of Contemporary Philosophy of Language

Zakkou, Julia (2019). Faultless Disagreement: A defense of Contextualism in the Realm of Personal Taste. Klostermann.

Zeman, Dan (2020). Faultless Disagreement. In Martin Kusch (ed.), The Routledge Handbook of Philosophy of Relativism. Routledge. pp. 486-495. 